\section{Impact of cross-national diffusion process in telecommunications demand forecasting}

\author{
Christos Michalakelis \\ Georgia Dede \\ Dimitrios Varoutas \\ \& Thomas Sphicopoulos \\ University of Athens \\ Department of Informatics and Telecommunications, \\ Panepistimiopolis, Ilisia, Athens \\ GREECE 15784 \\ \{michalak; std01026; arkas; thomas\}@di.uoa.gr
}

$$
\text { Tel: }+302107275318
$$

Fax: +302107275601

\section{Abstract}

New product diffusion process studies focus mainly on estimating the adoption rate of the product, within the boundaries of the targeted market. However, and especially for high technology and telecommunications products, it is very likely the case that they are introduced simultaneously into a number of market segments, a fact that it is rarely taken into account. Thus, the effect of market and population interaction, and the consequent co-influence in the diffusion rates is not taken into account. This work focuses on developing and evaluating a pertinent methodology, so as to capture this cross-national interaction influence in the diffusion process.

\section{Introduction}

Since the analysis of new products growth rate was given attention, enough research was carried out, considering diffusion in targeted markets and areas [12], like the telecommunications sector [11]. However, the main focus was limited into the areas and the corresponding populations of these markets, and the factors affecting the diffusion process, not considering the case that the same product is simultaneously introduced in two, or more, markets in neighboring areas. In this case the factor of population interaction, which may affects the diffusion shape, is disregarded. This is the case of telecommunication products and services, where any new technology is quite possible to be introduced in more than one market, each one having its own economic and cultural characteristics.

Whenever such a new telecommunication product is introduced at the same time in a number of areas, such as countries, diffusion processes are expected to reveal differences in the corresponding shapes. This is due to the differences of the considered markets which may refer to introduction prices [1], household incomes [6], product advertising, marketing strategies, or other characteristics of the target population and areas [7]. Not only in the case of simultaneous product introduction, but also the case of a "lead-lag" situation, where there is a time lag between introduction of a new product among a number of areas, should be considered. When such an introduction happens into a country, this is expected to affect the product's penetration among the population of the neighboring areas, even if the product will be introduced in some future time.

The main reason for these considerations is that nowadays people from various countries, or areas in the same country, interact with each other thus being influenced [4]. This influence affects the diffusion progress of many products, telecommunication products in particular. For this reason, the study of a "crossnational" product's diffusion process, should take under consideration the "cross-area" influence, described above. This work focuses on developing a framework and a corresponding methodology to accommodate the interaction and influence in the diffusion shapes described above. An aggregate diffusion model is then developed, to estimate the amount of influence, in each direction.

\section{Previous research}

Despite the fact that cross-national diffusion turned out to be an important and interesting field of research, especially for market managers dealing with international markets, not much of work has the literature to present. Among them [10], Gatignon, Eliashberg and Robertson (GER), Takada and Jain (TJ), and Helsen, Jedidi kal Desarbo (HJD) have some significant work to present, in studying the cross-national diffusion process. Their results can be summarized in the following:

1. New product's diffusion process is based mainly on the market's culture (TJ), and differences in penetration are explained by factors describing the specific country, such as mobility, cosmopolitanism, percentage of employed women etc. (GER) 
2. The later a product is introduced in a country's market, the faster the expected adoption rate. A "lead-lag" influence exists that explains the fast adoption rate in the lag country. This refers to the so called "timelag" influence (TJ).

3. Market segments, based on the diffusion parameters, are not constant. Instead they are dependent on the nature of the considered product, each time (HJD)

\section{Diffusion models}

Diffusion models are mathematical functions of time, used to estimate the parameters of the diffusion process of a product's life cycle at an aggregate level, without taking in consideration the underlying specific parameters that drive the process.

The most well-known representatives of the models developed for diffusion estimation, are the Bass model [2] (Bass, 1969), Fisher - Pry model (Fisher \& Pry, 1971), logistic family models (Bewley \& Fiebig, 1988), as well as the Gompertz model [5]. Logistic models and variations of the Gompertz model provide S- shaped curves which are used in common in forecasting diffusion of products or services. These models are used to describe and forecast demand and diffusion at the aggregate level, which is the total market response rather than at the individual customer level [3] (this approach is described by the so called choice-based models focusing on the probability of individuals to adopt the innovation whose market behaviour is driven by maximization of preferences, as modern economic choice theory assumes). S-shaped patterns derive from the differential equation

$\frac{d Y(t)}{d t}=\delta^{*} Y(t) *[S-Y(t)]$,

In Equation 1, $\mathrm{Y}(\mathrm{t})$ represents total penetration at time $\mathrm{t}, \mathrm{S}$ the saturation level of the specific technology and $\delta$ is a constant of proportionality, the so-called coefficient of diffusion. Penetration is defined as the proportion of the population that uses the product or service being examined.

At the time that the particular technology is introduced $(t=0)$, there is a critical mass, the innovators that initially adopt it. This number influences the rate of diffusion and the time of saturation is met.
In the context of this work, the Linear Logistic Model is used, after necessary development in order to accommodate the cross-area influence.

The general form of the logistic models family is:

$Y(t)=\frac{S}{1+e^{f(t)}}$,

where $Y(t)$ is the estimated diffusion level and $S$ the saturation level. $f(t)$ is given by the following formula:

$$
f(t)=-a-b^{*} t(m, k),
$$

where $\mathrm{t}(\mathrm{m}, \mathrm{k})$ is a non-linear function of time (except the linear logistic model, where $\mathrm{t}(\mathrm{m}, \mathrm{k})=\mathrm{t})$ and is given by one of the following formulations, according to the model's construction.

The Linear instance of the model is given by

$\mathrm{t}(\mathrm{m}, \mathrm{k})=\mathrm{t}$

The linear logistic model is also known as Fisher - Pry model (Fisher, 1971).

\section{Development of the proposed model}

If the case of simultaneous effect among the diffusion processes of a new product in two countries is considered then, in order to capture the effect of diffusion in one country on diffusion in the other, the diffusion in each country is modeled as [9]:

$\frac{d F_{i}(t)}{d t}=\delta_{i} * F_{i}(t) *\left[S_{i}-F_{i}(t)\right]^{*} x_{i}(t)$,

where $F_{i}(t)$ is the cumulative penetration at time $t$ and $x_{i}(t)$ is the current marketing effort term which should include only those effects that are happening at time $t$ and influence the adoption rate. In order to model the 
impact of diffusion of the second country on the first country's diffusion, $x_{i}(t)$ is modeled as [8]:

$x_{2}(t)=1+\left(b_{21} *\right.$ change at time $t$ in diffusion rate of 2 nd country $)$

In Equation 6, 1 represents the natural time, the diffusion force is simply the cumulative adoption up to $\mathrm{t}$, and $b_{21}$ measures the impact of Country 2's diffusion on Country 1's diffusion. This can be represented by:

$x_{2}(t)=1+\left(b_{21} * \frac{d F_{2}(t)}{d t}\right)$

By considering the same differential equation for the other country, the following set of equations is derived:

$F_{1}(t)=S_{1} * \frac{1}{1+\mathrm{e}^{-a_{1}-b_{1} *\left(t+b_{21} F_{2}(t)\right)}}$

$F_{2}(t)=S_{2} * \frac{1}{1+\mathrm{e}^{-a_{2}-b_{2} *\left(t+b_{12} F_{1}(t)\right)}}$

The set of equations (7) and (8) are solved simultaneously, in an iterative way, by following the next steps [9]:

1. Assign a value of 0 to $F_{1}(t), F_{2}(t)$ on the right-hand side of Equations (7) and (8).

2. Estimate $a_{i}, b_{i}, S_{i}$ of the two resulting equations. Call them $\left(a_{1}, b_{1}, S_{1}, a_{2}, b_{2}, S_{2}\right)_{0}$.

3. Using $\left(a_{i}, b_{i}, S_{i}\right)_{0}$ and using 0 for F1 and F2 on the right-hand sides, evaluate $F_{1}(t), F_{2}(t)$ of Equations (7) and (8). Call these $\left(F_{1}(t), F_{2}(t)\right)_{1}$.
4. Assign $\left(F_{1}(t), F_{2}(t)\right)_{0}$ to the $\mathrm{F} 1(\mathrm{t})$ and $\mathrm{F} 2(\mathrm{t})$ on the right-hand side of Equations (7) and (8) and estimate $a_{1}, b_{1}, S_{1}, b_{21}, a_{2}, b_{2}, S_{2}, b_{12}$. Call them $\left(a_{1}, b_{1}, S_{1}, b_{21}, a_{2}, b_{2}, S_{2}, b_{12}\right)_{1}$.

5. Using $\left(a_{1}, b_{1}, S_{1}, b_{21}, a_{2}, b_{2}, S_{2}, b_{12}\right)_{1}$ and using $\left(F_{1}(t), F_{2}(t)\right)_{1}$ for $\mathrm{F} 1(\mathrm{t})$ and $\mathrm{F} 2(\mathrm{t})$ on the right-hand sides, evaluate $F_{1}(t), F_{2}(t)$ of Equations (7) and (8). Call these $\left(F_{1}(t), F_{2}(t)\right)_{2}$.

6. Assign $\left(F_{1}(t), F_{2}(t)\right)_{2}$ to $F_{1}(t), F_{2}(t)$ on the right-hand side of Equations (7) and (8) and estimate $\left(a_{1}, b_{1}, S_{1}, b_{21}, a_{2}, b_{2}, S_{2}, b_{12}\right)_{1}$ of the two resulting equations. Call them $\left(a_{1}, b_{1}, S_{1}, b_{21}, a_{2}, b_{2}, S_{2}, b_{12}\right)_{2}$

7. Repeat Steps 5 and 6 until no changes in the estimates of $a_{1}, b_{1}, S_{1}, b_{21}, a_{2}, b_{2}, S_{2}, b_{12}$ are found.

The above procedure is implemented by using a genetic algorithms approach. The objective function for the algorithm was the minimization of the squares of the errors, between the actual and the estimated values of penetration. 


\section{Evaluation of the proposed methodology}

This section is devoted in the evaluation of the so far developed methodology, over mobile phone, and broadband diffusion data. The corresponding results are presented and discussed.

\subsection{Eastern - Western Europe}

Table 1: Diffusion of mobile phones over population, Eastern Western Europe (actual data) (Source: Eurostat)

\begin{tabular}{lll} 
Year & $\begin{array}{l}\text { Eastern Europe } \\
\text { F1(t) }\end{array}$ & $\begin{array}{l}\text { Western Europe } \\
\text { F2(t) }\end{array}$ \\
\hline \hline 1999 & 0,0385 & 0,43670 \\
2000 & 0,0759 & 0,68640 \\
2001 & 0,1353 & 0,81730 \\
2002 & 0,2057 & 0,87120 \\
2003 & 0,2992 & 0,94149 \\
2004 & 0,3971 & 1,00320 \\
2005 & 0,4565 & 1,03620
\end{tabular}

Table 2: Initial estimation of parameters

\begin{tabular}{lll} 
& Eastern Europe & Western Europe \\
\hline \hline $\mathrm{S}$ & 0,560258 & 1,025588 \\
$\mathrm{a}$ & $-3,22$ & $-0,93592$ \\
$\mathrm{~b}$ & 0,676114 & 0,740675
\end{tabular}

Table 3: Final estimation of parameters

\begin{tabular}{lll} 
& Eastern Europe & Western Europe \\
\hline \hline $\mathrm{S}$ & 0,5802 & 1,025588 \\
$\mathrm{a}$ & $-3,22$ & $-0,93592$ \\
$\mathrm{~b}$ & 0,676114 & 0,740675 \\
& $\mathrm{~b} 21=0,0155$ & $\mathrm{~b} 12=0,0000$
\end{tabular}

Table 4: Adjusted diffusion estimation after cross-national methodology application

\begin{tabular}{lll} 
Year & Eastern Europe & Western Europe \\
\hline 1999 & 0,041526 & 0,46289 \\
2000 & 0,075969 & 0,64927 \\
2001 & 0,131764 & 0,80354 \\
2002 & 0,210882 & 0,90619 \\
2003 & 0,304066 & 0,96497 \\
2004 & 0,392472 & 0,99576 \\
2005 & 0,460685 & 1,01115 \\
2006 & 0,50539 & 1,01865 \\
2007 & 0,531639 & 1,02227 \\
2008 & 0,546066 & 1,02400 \\
2009 & 0,553708 & 1,02483 \\
2010 & 0,557678 & 1,02523
\end{tabular}

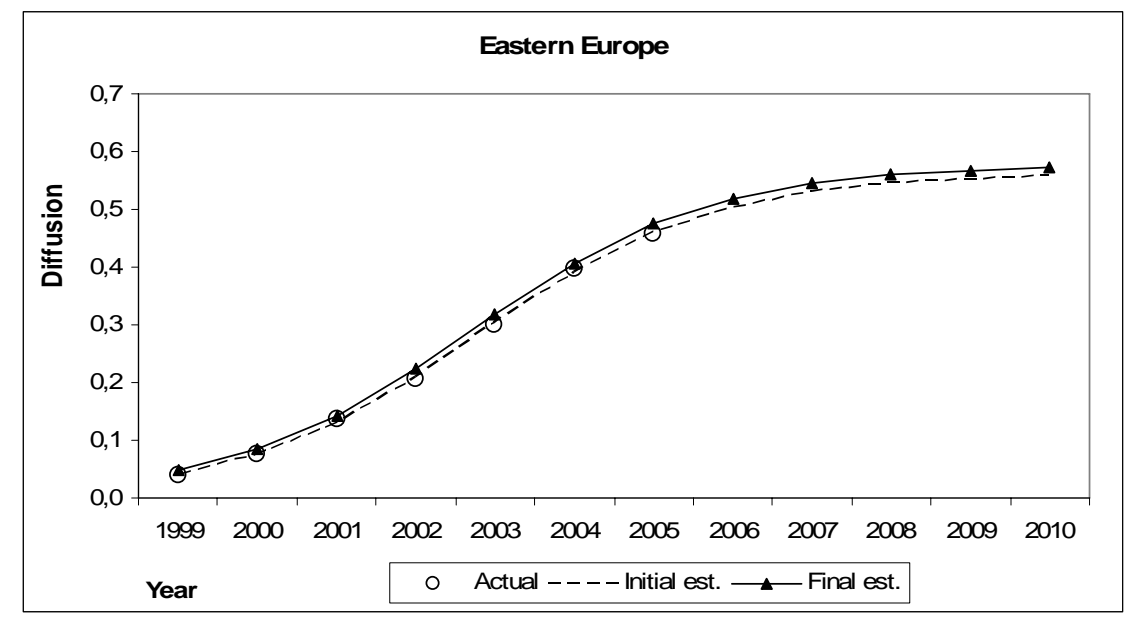

Figure 1 Cross-national diffusion results, Eastern Europe 


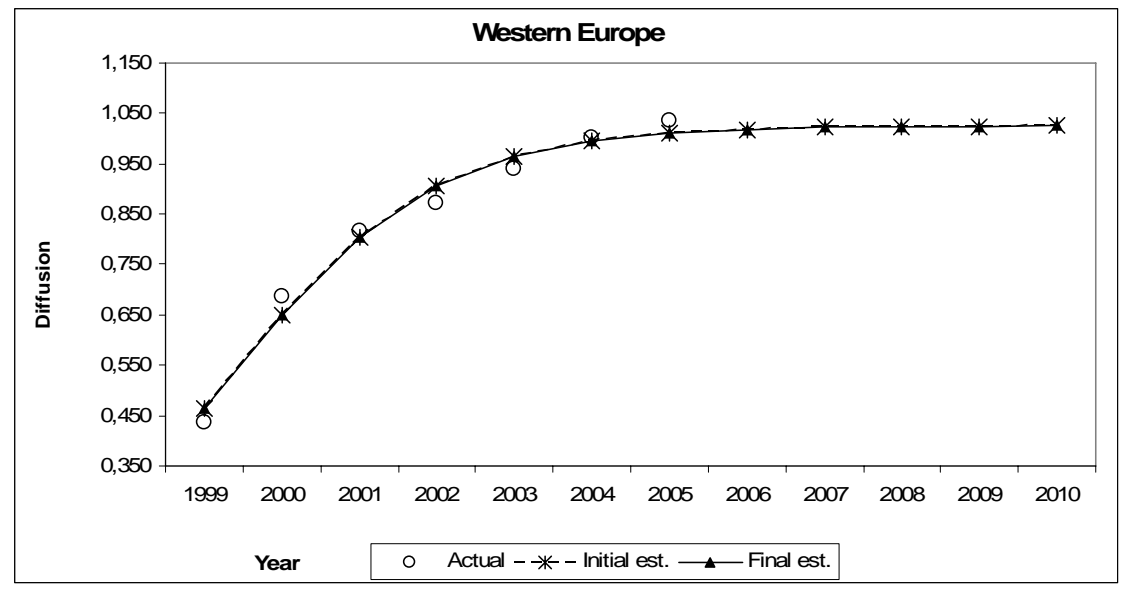

Figure 2 Cross-national diffusion results, Western Europe

The direct observations of the results presented above, are that Eastern Europe is expected to be influenced by Western Europe and not vice-versa. Figure 1 depicts this influence and the corresponding change in the diffusion process, by revealing the corresponding adjustments to the initially estimated parameters, whereas Figure 2 shows the unchanged shape in Western Europe's diffusion. Moreover, Western Europe's influence speeds up Eastern Europe's diffusion process, thus meeting saturation level penetration earlier than initially estimated. Initially estimated saturation level value remains unchanged, only the diffusion speed for meeting this saturation level is affected. The observed results are coherent with what someone would expect, as Western Europe's countries, like Germany or Sweden, where adoption rates in technology products are remarkably high, have a higher technological level to present than that of Eastern Europe's. In addition, Western Europe's countries have a higher mean GDP and GDP per capita, than the corresponding values for Easters Europe's countries. Figure 3 depicts the change in the diffusion rate of mobile telephony in Eastern Europe before and after the application of the methodology.

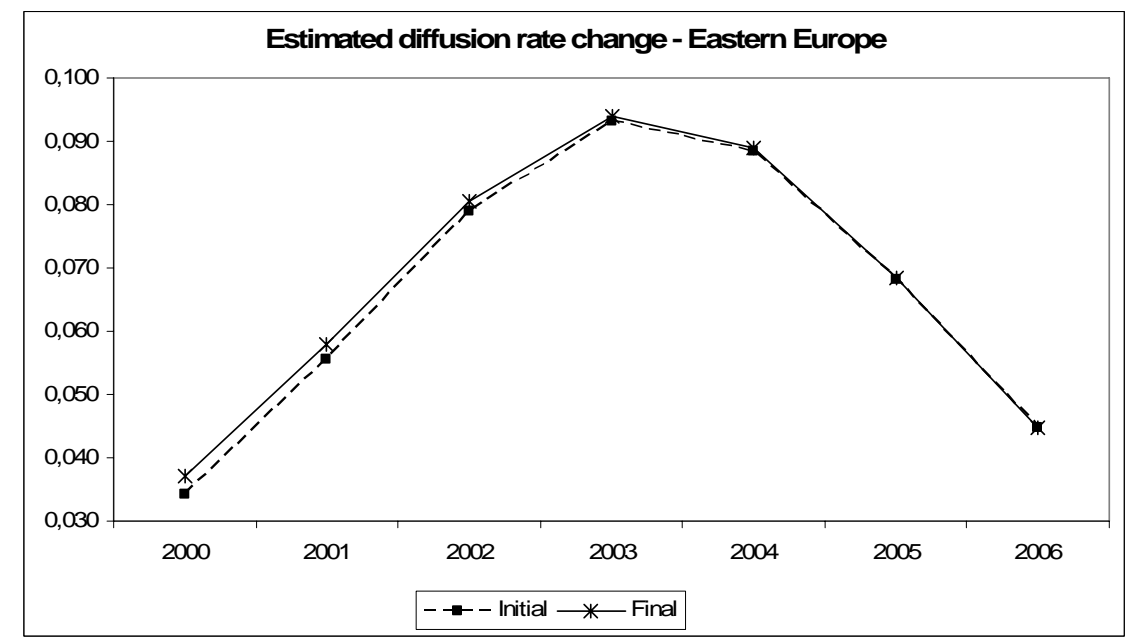

Figure 3 Change in estimated diffusion rate due to cross-national influence, Eastern Europe

\subsection{Latin - North America}

Table 5: Diffusion of mobile phones over population, Latin - North America (actual data) (Source: Eurostat)

\begin{tabular}{lll} 
Year & $\begin{array}{l}\text { Latin America } \\
\text { F1(t) }\end{array}$ & $\begin{array}{l}\text { North America } \\
\text { F2(t) }\end{array}$ \\
\hline \hline 1999 & 0,0902 & 0,33 \\
2000 & 0,1375 & 0,4048 \\
2001 & 0,1804 & 0,4862 \\
2002 & 0,2112 & 0,4917 \\
2003 & 0,2574 & 0,5863 \\
2004 & 0,3102 & 0,5918 \\
2005 & 0,3542 & 0,6347
\end{tabular}


Table 6: Initial estimation of parameters

\begin{tabular}{lll} 
& Latin America & North America \\
\hline \hline $\mathrm{S}$ & 0,51706 & 0,692874 \\
$\mathrm{a}$ & $-1,80652$ & $-0,45926$ \\
$\mathrm{~b}$ & 0,367356 & 0,393623
\end{tabular}

Table 7: Final estimation of parameters

\begin{tabular}{lll} 
& Latin America & North America \\
\hline \hline $\mathrm{S}$ & 0,53170 & 0,692874 \\
$\mathrm{a}$ & $-1,80652$ & $-0,45926$ \\
$\mathrm{~b}$ & 0,367356 & 0,393623 \\
& $\mathrm{~b} 21=0,00013$ & $\mathrm{~b} 12=0,0000$
\end{tabular}

Table 8: Adjusted diffusion estimation after cross-national methodology application

\begin{tabular}{lll} 
Year & $\begin{array}{l}\text { Latin America } \\
\text { F1(t) }\end{array}$ & $\begin{array}{l}\text { North America } \\
\text { F2(t) }\end{array}$ \\
\hline \hline 1999 & 0,09915 & 0,33507 \\
2000 & 0,13194 & 0,40275 \\
2001 & 0,17112 & 0,46628 \\
2002 & 0,21543 & 0,52181 \\
2003 & 0,26252 & 0,56739 \\
2004 & 0,30934 & 0,60292 \\
2005 & 0,35294 & 0,62951 \\
2006 & 0,39112 & 0,64882 \\
2007 & 0,42280 & 0,66253 \\
2008 & 0,44792 & 0,67211 \\
2009 & 0,46715 & 0,67873 \\
2010 & 0,48146 & 0,68327
\end{tabular}

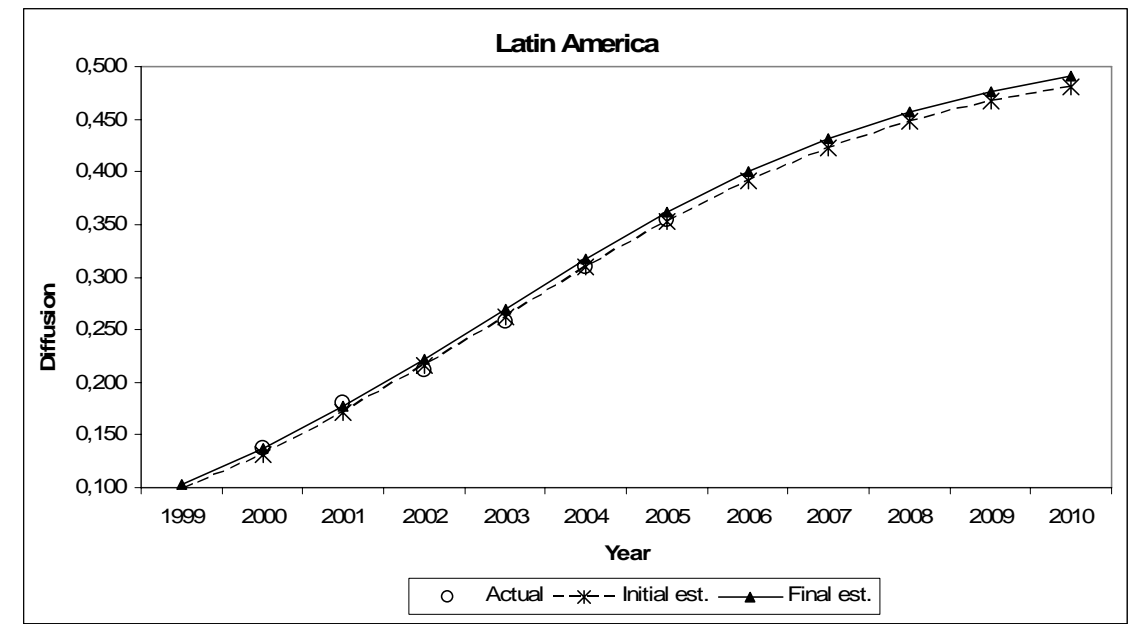

Figure 4 Cross-national diffusion results, Latin America

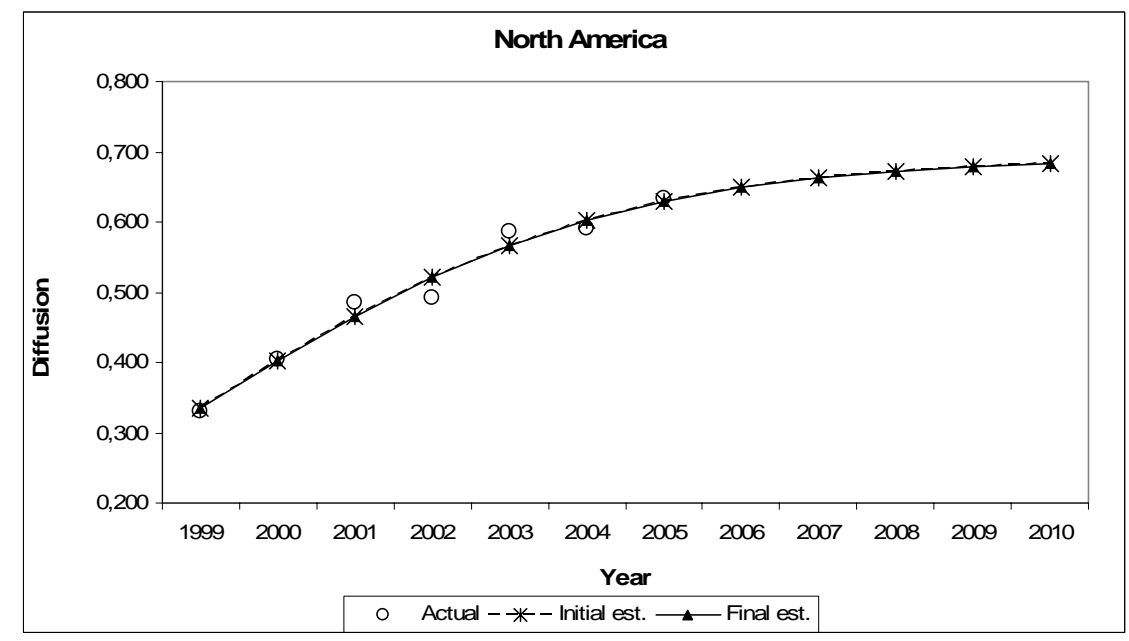

Figure 5 Cross-national diffusion results, North America 
Inspection of the results presented above, reveals that North America influences Latin America by a factor of b21 $=0,00013$. The physical meaning of the parameter b21, is that each year's adoption rate in Latin America, is adjusted by 0,00013 times the diffusion rate of North America, for the same year.

On the other hand, North America's diffusion shape is not influenced at all. This is in accordance with the expected outcomes, as North America has a higher technological maturity, than Latin America, as USA and Canada's industrialization level cannot be compared with Latin America's countries. Mean household incomes are also quite different between populations of the areas considered.

\subsection{Greece - Italy}

\section{Table 9: Diffusion of isdn connections, Greece - Italy (actual data)} (Source: OECD)

\begin{tabular}{lll} 
Year & $\begin{array}{l}\text { Greece } \\
\text { F1 (t) }\end{array}$ & $\begin{array}{l}\text { Italy } \\
\text { F2(t) }\end{array}$ \\
\hline \hline 1996 & 0,0001 & 0,0019 \\
1997 & 0,0001 & 0,0050 \\
1998 & 0,0004 & 0,0113 \\
1999 & 0,002661091 & 0,043844 \\
2000 & 0,009190828 & 0,079629 \\
2001 & 0,018930431 & 0,093476 \\
2002 & 0,026119403 & 0,101818 \\
2003 & 0,029315665 & 0,102117
\end{tabular}

Table 10: Initial estimations

\begin{tabular}{lll} 
& Greece & Italy \\
\hline \hline $\mathrm{S}$ & 0,030228 & 0,101844 \\
$\mathrm{a}$ & $-13,3714$ & $-12,7713$ \\
$\mathrm{~b}$ & 1,389228 & 1,557124
\end{tabular}

Table 11: Final estimations

\begin{tabular}{lll} 
& Greece & Italy \\
\hline \hline $\mathrm{S}$ & 0,033506 & 0,101844 \\
$\mathrm{a}$ & $-13,37139249$ & $-12,7713$ \\
$\mathrm{~b}$ & 1,38922807 & 1,557124 \\
& $\mathrm{~b} 21=0,02556$ & $\mathrm{~b} 12=0,0002$
\end{tabular}

Table 12: Adjusted diffusion estimation after cross-national methodology application

\begin{tabular}{lll} 
Year & $\begin{array}{l}\text { Greece } \\
\text { F1 (t) }\end{array}$ & $\begin{array}{l}\text { Italy } \\
\text { F2(t) }\end{array}$ \\
\hline \hline 1996 & $6,69975 E-05$ & 0,00069 \\
1997 & 0,000278974 & 0,00320 \\
1998 & 0,001123827 & 0,01358 \\
1999 & 0,003988068 & 0,04298 \\
2000 & 0,011004881 & 0,07904 \\
2001 & 0,021477486 & 0,09601 \\
2002 & 0,028962461 & 0,10055 \\
2003 & 0,031811527 & 0,10157 \\
2004 & 0,032617561 & 0,10179 \\
2005 & 0,032825153 & 0,10183 \\
2006 & 0,032877297 & 0,10184 \\
2007 & 0,032890313 & 0,10184
\end{tabular}




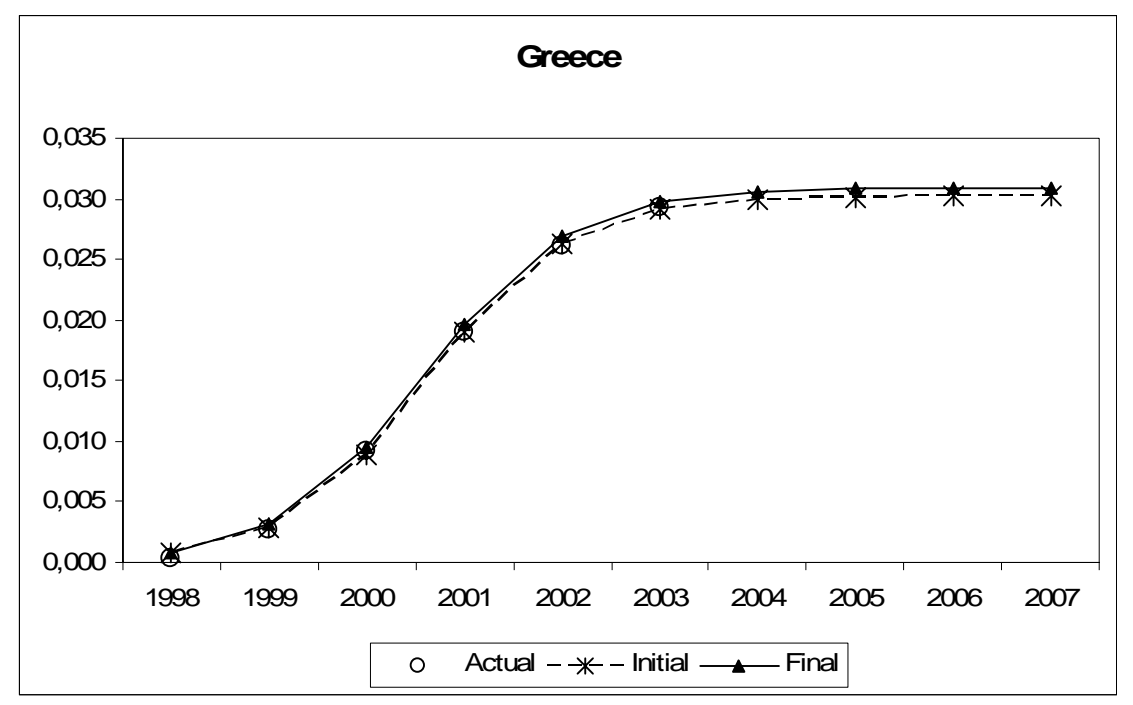

Figure 6 Cross- national diffusion results, Greece

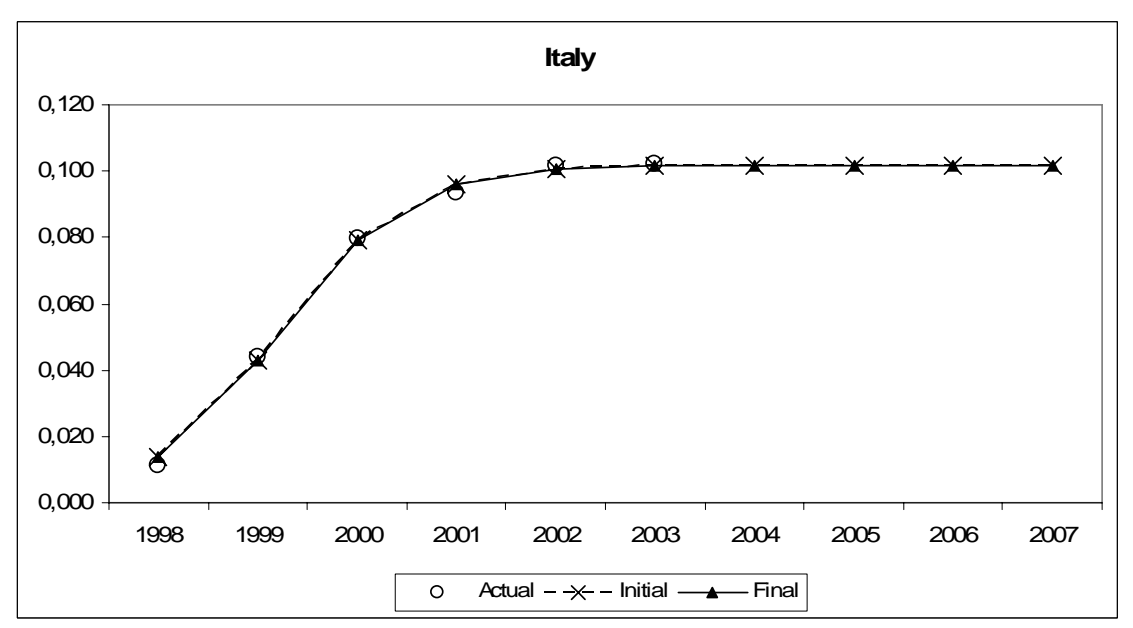

Figure 7 Cross-national diffusion results, Italy
As clearly shown, Italy turns out to influence Greece, than vice-versa, and this could be explained due to the higher technological adoption status of the Italians, than this of the Greeks. Moreover, isdn technology was firstly introduced to Italian telecommunications market, in 1993, and after two year to the Greek market. Figure 6 andFigure 7 present the graphical results for each country, where the adjustment to Greece's initially estimated diffusion rate can be observed, whereas the negligible impact of Greece's diffusion leaves Italy's adoption rate practically unchanged.

\section{Conclusions}

This work intends to capture the cross-national diffusion effects, whenever a new product is introduced in a number of markets with different characteristics. The definition of cross-national, is not limited to country segmentation, but can be extended to include all kinds of market segmentation, like different areas in the same country, or continents in the whole. Given that definition, a study of interest would be the validation of the methodology, over the diffusion process of a telecommunications product, within the boundaries of the same country. This could give an estimation of the influence of the capital city of the country, or other major cities, over the decentralized areas, and the impact on the initially estimated diffusion parameters, and adoption rates.

Moreover, as similar methodologies were evaluated over consumer durables only without considering the possible peculiarities of the telecommunications area, this work focused mainly on evaluating the interaction of telecommunication markets. At this point, it should be clarified that the application of such a methodology is not expected to reveal major changes, but calculate adjustments to the initially estimated diffusion parameters.

The methodology presented can be extended to capture the "lead-lag" effect, which is the case when a product is introduced in a number of markets with a time delay. The effects of the lead country over the lag one are expected to noticeably influence the adoption rate of the product within the lag country, as previous research has revealed that the later the product is introduced in the lag market, the greater the influence over the diffusion process would be.

Future work could also include the expansion of the methodology so as to capture the cross-area impact in more than two areas, focusing on the telecommunications sector products. Even more, development of such kind of diffusion models can be directed to accommodate the impact of other exogenous factors apart from cross-national influence, such as generation substitution impacts. 


\section{References}

[1] Baliamoune Mina N.. The New Economy and Developing Countries. UNU/WIDER, 10-11 May 2002, Helsinki.

[2] Bass Frank M., 1969. A new product growth for model consumer durables. Management Science, Vol. 15, No. 5, January 1969, pp. 215227.

[3] Bewley, R. \& Fiebig, D. (1998). A flexible logistic growth model with applications in telecommunications. International Journal of forecasting, 4, 177-192.

[4] Gatignon Hubert; Eliashberg Jehoshua; Robertson (Thomas S.). Modeling Multinational Diffusion Patterns: An Efficient Methodology. Marketing Science, Vol. 8, No. 3 (summer, 1989), 231-247.

[5] Gompertz, B. (1825). On the Nature of the Function Expressive of the Law of Human Mortality, and on a New Mode of Determining the Value of Life Contingencies. Philosophical Transactions of the Royal Society of London 115, pp. 513-585.

[6] Kauffman Robert J., Techatassanasoontorn (Angsana A.). Does one standard promote faster growth? An econometric analysis of the international diffusion of wireless technology. Fall 2002 INFORMS CIST Conference. Last revised: September 22, 2003.

[7] Kauffman Robert J., Techatassanasoontorn Angsana A.. International diffusion of digital mobile technology: A coupled-hazard approach. Forthcoming in Information Technology and Management. Last revised: June 2003.

[8] Kumar V.. New Product Forecasting. ISF 2002, Dublin, Ireland, June 27-30, 2002.

[9] Kumar V., Krishnan Trichy V.. Research Note. Multinational Diffusion Models: An Alternative Framework. Marketing Science, Vol. 21, No. 3, summer 2002, pp. 318-330.

[10] Kumar V., Ganesh Jaishankar, and Echambadi Raj. Cross-National Diffusion Research: what Do We Know and How Certain Are We? $J$ PROD INOV MANAG, 1998; 15:255-268.

[11] Mahajan, V., Muller, E. \& Bass F.M. (1990). New product diffusion models in marketing: A review and directions for research. Journal of Marketing. 54(1), 1-26.

[12] Stremersch Stefan, Tellis Gerard J.. Understanding and managing international growth of new products. International Journal of Research in Marketing 21 (2004), 421-438. 